\title{
PENGARUH MOTIVASI DAN DISIPLIN KERJA TERHADAP PRODUKTIVITAS KARYAWAN PADA PT. MEDIAINDO SEJAHTERA DI JAKARTA
}

\author{
Lucia Maduningtias \\ Program Studi Manajemen, Fakultas Ekonomi, Universitas Pamulang, Tangerang Selatan, Banten. \\ Email Corespondent : dosen01783@unpam.ac.id
}

\begin{abstract}
This study aims to determine the effect of motivation and work discipline on employee productivity at PT. Mediaindo Sejahtera in Jakarta. The method used is explanatory research with analytical techniques using statistical analysis with regression testing, correlation, determination and hypothesis testing. The results of this study have a significant effect on employee productivity by $46.7 \%$, the hypothesis test obtained $t$ count $>t$ table or (7.809> 2.003). Work discipline has a significant effect on employee productivity of $36.0 \%$, the hypothesis test is obtained t count $>t$ table or (5.608> 2.003). Motivation and work discipline simultaneously have a significant effect on employee productivity by 55.9\%, the hypothesis test is obtained $F$ count $>F$ table or (34.847> 2.770).
\end{abstract}

Keywords : Motivation, Work Discipline, Employee Productivity.

\begin{abstract}
Abstrak: Penelitian ini bertujuan untuk mengetahui pengaruh motivasi dan disiplin kerja terhadap produktivitas karyawan pada PT. Mediaindo Sejahtera di Jakarta. Metode yang digunakan adalah explanatory research dengan teknik analisis menggunakan analisis statistik dengan pengujian regresi, korelasi, determinasi dan uji hipotesis. Hasil penelitian ini motivasi berpengaruh signifikan terhadap produktivitas karyawan sebesar 46,7\%, uji hipotesis diperoleh $t$ hitung $>t$ tabel atau $(7,809>2,003)$. Disiplin kerja berpengaruh signifikan terhadap produktivitas karyawan sebesar 36,0\%, uji hipotesis diperoleh $t$ hitung $>t$ tabel atau $(5,608>2,003)$. Motivasi dan disiplin kerja secara simultan berpengaruh signifikan terhadap produktivitas karyawan sebesar 55,9\%, uji hipotesis diperoleh $F$ hitung $>F$ tabel atau $(34,847>2,770)$
\end{abstract}

Keywords : Motivasi, Disiplin Kerja, Produktivitas Karyawan 


\section{PENDAHULUAN}

Perusahaan yang mampu bertahan dengan baik salah satunya memiliki karyawan atau sumberdaya manusia yang mampu bekerja dengan baik guna mewujudkan tujuan yang diharapkan oleh perusahaan. Dalam hal ini, setiap perusahaan membutuhkan sumber daya manusia yang memiliki produktivitas yang tinggi, sehingga dapat memberikan hasil yang maksimal bagi perusahaan.

Agar perusahaan bisa bersaing, maka tuntutan kesadaran akan pentingnya kualitas Sumber Daya Manusia (SDM) yang merupakan salah satu respon dalam menyikapi perubahan tersebut sangatlah penting. Sumber Daya Manusia (SDM) yang berkualitas sangat penting artinya bagi suatu perusahaan. Bahkan ketersediaan SDM berkualitas diyakini sebagai kunci utama keberhasilan. Oleh karena itu, untuk mewujudkan SDM yang berkualitas, perlunya peran serta yang optimal dari pihak perusahaan sendiri sebagai wadahpengembangan bagi SDM itu sendiri (investasi SDM)

Karena sumber Daya Manusia (SDM) merupakan sumber daya paling vital yang menjadi penentu keberhasilan suatu perusahaan, oleh sebab itu perlu diberikan hak-hak yang dapat memacu meningkatkan produktivitasnnya, ada beberapa faktor yang dapat mendorong karyawan meningkatkan produktivitasnya antara salah satunya adalah pemberian disiplin yang dilakukan pemimpin di perusahaan kepada karyawan.

Sumber daya manusia sebagai unsur utama pada suatu lembaga memiliki peranan yang sangat besar dalam upaya mencapai tujuan yang telah ditetapkan. Peran sumber daya manusia ini kemudian berkembang mengikuti perkembangan organisasi, ilmu pengetahuan dan teknologi. Sumber daya manusia memegang peranan yang sangat menentukan karena bagaimanapun hebat dan canggihnya teknologi yang digunakan tanpa didukung oleh manusia sebagai pelayan operasionalnya, tidak akan mampu menghasilkan suatu output yang sesuai dengan tingkat efisiensi yang tinggi. Oleh karna itu pengembangan sumber daya manusia dalam suatu organisasi menjadi sangat penting.

Untuk mendapatkan sumber daya manusia yang diharapkan oleh organisasi agar memberikan andil positif terhadap semua kegiatan perusahaan dalam mencapai tujuannya, setiap karyawan diharapkan memiliki disiplin kerja yang tinggi sehingga nantinya akan meningkatkan produktivitas yang tinggi. Motivasi menurut Kreitner dan Kinicki dalam Wibowo (2016:322), "Motivasi merupakan proses psikologis yang membangkitkan dan mengarahkan prilaku pada pencapaian tujuan atau goal-directed behavior". Manajer perlu memahami proses psikologis ini apabila mereka ingin berhasil membina pekerja menuju pada penyelesaian sasaran organisasi.

Mengingat pentingnya motivasi bagi setiap karyawan, maka perusahaan perlu terus menjaga agar disiplin karyawan tidak menurun. Satu hal yang perlu dipahami setiap karyawan bekerja karena ingin memenuhi kebutuhannya, baik kebutuhan yang disadari maupun kebutuhan yang tidak disadari. Dengan memenuhi kebutuhankebutuhan tersebut tentu akan medisiplin karyawan dalam bekerja akan meningkat dan berdampak pada produktivitas yang baik dan membantu perusahaan mencapai tujuannya. Motivasi Disiplin yang baik mencerminkan besarnya rasa tanggung jawab seseorang terhadap tugas-tugasnya yang diberikan kepadanya. Hal ini mendorong gairah kerja, dan terwujudnya tujuan perusahaan, karyawan, dan masyarakat. Oleh karena itu, setiap manajer selalu berusaha agar pada bawahannya mempunyai motivasi yang baik. Seorang manajer dikatakan efektif dalam kepemimpinannya, jika karyawannya berdisiplin baik. Untuk memelihara dan meningkatkan kedisiplinan yang baik adalah hal yang sulit. Karna banyak faktor yang mempengaruhinya.

Peraturan sangat diperlukan untuk memberikan bimbingan dan penyuluhan bagi karyawan PT. Mediaindo Sejahtera dalam menciptakan tata tertib yang baik, semangat kerja, moral kerja, efisiensi, dan efektivitas kerja karyawan akan meningkat. Jika karyawan PT. Mediaindo Sejahtera tidak mematuhi peraturan-peraturan perusahaan tersebut, akan sulit mencapai tujuannya perusahaan. Kedisiplinan suatu perusahaan dikata baik, jika sebagian besar karyawan mentaati peraturanperaturan yang ada.

Kedisiplinan adalah fungsi operatif keenam (yaitu: perencanaan, pengorganisasian, pengarahan, pengawasan, pengendalian, pengadaan) dari manajer sumber daya manusia. Kedisiplinan merupakan fungsi manajemen sumber daya manusia yang terpenting, karena semakin baik disiplin karyawan, semakin tinggi prestasi kerja yang dapat di capainya. Tanpa disiplin karyawan yang baik, sulit bagi organisasi mencapai hasil yang optimal.

Menurut Sutrisno (2016:99) produkivitas adalah hubungan antara keluaran (barang-barang atau jasa) dengan masukan (tenaga kerja, bahan, uang). Produktivitas merupakan ukuran efisiensi produktif. Suatu perbandingan antara hasil keluaran dan masukan. Masukan sering dibatasi dengan tenaga kerja, sedangkan keluaran diukur dalam kesatuan fisik, bentuk, dan nilai. Menurut Sutrisno (2016:101) ada tiga aspek utama yang perlu ditinjau dalam menjamin produktivitas yang tinggi yaitu: a) Aspek kemampuan manajemen tenaga kerja, b) Aspek efesiensi tenaga kerja, c) Aspek kondisi lingkungan pekerjaan. 
Ketiga aspek tersebut saling berkaitan dan terpadu dalam suatu sistem dan dapat diukurdengan berbagai ukuran yang relatif sederhana. Produktivitas harus menjadi bagian yang tak boleh dilupakan dalam penyusunan strategi bisnis yang mencakup bidang produksi, pemasaran, keuangan dan bidang lainnya.

Suatu kerja individu dapat ditingkatkan apabila ada kesesuaian antara pekerjaan dan kemampuannya. Salah satu program manajemen sumber daya manusia adalah menempatkan karyawan pada tempatnya, atau sesuai kemampuan kerjaannya. Program ini ditetapkan untuk mengatasi karyawan yang lambat, tidak semangat, dan tidak teliti.

Jika karyawan yang dipekerjakan tidak memiliki produktivitas yang baik yang dibutuhkan perusahaan, maka perusahaan tidak akan mencapai target yang sudah ditetapkan, dan merugikan perusahaan itu sendiri. Oleh sebab itu, dalam penarikan, seleksi, penempatan karyawan harus berdasarkan azas the right man in the right place, and the right man in the right job, yang artinya karyawan perlu ditempatkan pada pekerjaan yang sesuai dengan kemampuannya sangatlah penting untuk mencapai tujuan perusahaan dan produktivitas karyawan yang lebih optimal.

Berdasarkan hasil pengamatan diketahui bahwa absensi dari tahun ke tahun mengalami peningakatan ditunjukkan dengan angka presentase yang semakin besar. Sesuai hasil temuan awal peneliti, peneliti menemukan tingginya tingkat absensi karyawan di PT. Mediaindo Sejahtera di Jakarta dari terus mengalami peningkatan, hal ini jika tidak segera dilakukan tindakan maka akan berdampak buruk bagi pencapaaian tujuan perusahaan, untuk itu pemimpin perusahaan harus lebih memperhatikan pemberian disiplin yang ada di perusahaan agar karyawan dapat kembali bersemangat bekerja dan menunjukan produktivitas yang baik dalam membantu tercapainya tujuan perusahaan.

Berdasarkan uraian di atas, maka penulis tertarik untuk mengadakan penelitian dengan judul "Pengaruh Motivasi Dan Disiplin Terhadap Produktivitas Karyawan Pada PT. Mediaindo Sejahtera di Jakarta".

\section{TINJAUAN PUSTAKA}

\section{Motivasi}

Danang Sunyoto (2016:11), motivasi membicarakan tentang bagaimana cara mendorong semangat kerja seseorang, agar mau bekerja dengan memberikan kemampuan dan keahliannya secara optimal guna mencapai tujuan organisasi. Motivasi menjadi penting karena dengan motivasi diharapkan setiap karyawan mau bekerja keras dan antusias untuk mencapai produktifitas kerja yang tinggi. Perilaku seseorang dipengaruhi dan dirangsang oleh keinginan, pemenuhan kebutuhan serta tujuan dan kepuasannya. Rangsangan timbul dari dalam dan dari luar. Rangsangan ini akan menciptakan dorongan pada seseorang untuk melakukan aktifitas

\section{Disiplin kerja}

Menurut Sutrisno (2016) mendefinisikan "Disiplin adalah perilaku seseorang yang sesuai dengan peraturan, prosedur kerja yang ada atau sikap dan tingkah laku serta perbuatan yang sesuai dengan peraturan dari organisasi baik tertulis maupun tidak tertulis". Dalam penelitian ini indikator yang digunakan meliputi: taat terhadap aturan waktu taat terhadap aturan organisasi, taat terhadap aturan perilaku dalam pekerjaan, taat terhadap peraturan lainnya.

\section{Produktivitas Karyawan}

Menurut Simamora

(2017:612) berpendapat Produktivitas kerja merupakan perbandingan antara hasil yang dicapai seseorang dengan target yang ditetapkan dalam waktu tertentu dengan sumber daya yang digunakan. Lebih lanjut disampaikan bahwa indikator produktivitas menurut Simamora (2017:612) indikator yang digunakan dalam pengukuran produktivitas kerja meliputi kuantitas kerja, kualitas kerja dan ketepatan waktu

\section{METODE PENELITIAN}

\section{Populasi}

Populasi merupakan sekumpulan objek yang ditentukan melalui suatu kriteria tertentu yang akan dikategorikan ke dalam objek yang akan diteliti. Menurut Sugiyono (2016) mendefinisikan populasi adalah jumlah wilayah generalisasi yang terdiri atas obyek atau subyek yang mempunyai kualitas dan karakteristik yang ditetapkan oleh peneliti dan kemudian ditarik kesimpulannya. Adapun populasi dalam penelitian berjumlah 58 responden PT. Mediaindo Sejahtera di Jakarta

\section{Sampel}

Menurut Sugiyono (2016) yaitu "Sampel adalah jumlah dan karakteristik yang dimiliki oleh populasi tersebut". Sedangkan Suharsini Arikunto (2010) berpendapat bahwa "Sampel adalah sebagian atau wakil populasi yang diteliti”. Teknik pengambilan sampling dalam 


\section{b. Uji Multikonilieritas}

Pengujian mutlikolinearitas dilakukan untuk meyakini bahwa antar variabel bebas tidak memiliki multikolinearitas atau tidak memiliki pengaruh korelasi antara variabel yang ditetapkan sebagai model dalam penelitian. Uji multikolinearitas dilakukan dengan melihat nilai Tolerance Value dan Variance Inflation Factor (VIF). Adapun hasil pengujiannya sebagai berikut:

Tabel 3 Hasil Uji Multikolinieritas dengan

Collinierity Statistic.

\begin{tabular}{|c|c|c|c|c|c|}
\hline \multirow[b]{2}{*}{ Model } & \multicolumn{2}{|c|}{$\begin{array}{l}\text { Unstandardized } \\
\text { Coefficients }\end{array}$} & \multirow{2}{*}{$\begin{array}{c}\text { Standardized } \\
\text { Coefficients } \\
\text { Beta }\end{array}$} & \multicolumn{2}{|c|}{$\begin{array}{l}\text { Collinearity } \\
\text { Statistics }\end{array}$} \\
\hline & B & $\begin{array}{l}\text { Std. } \\
\text { Error }\end{array}$ & & Tolerance & VIF \\
\hline 1 (Constant) & 10.188 & 3.589 & & & \\
\hline $\begin{array}{l}\text { Motivasi } \\
\text { (X1) }\end{array}$ & .429 & .086 & .512 & .759 & 1.317 \\
\hline $\begin{array}{l}\text { Disiplin } \\
\text { Kerja } \\
\text { (X2) }\end{array}$ & .331 & .098 & .348 & .759 & 1.317 \\
\hline
\end{tabular}

Berdasarkan hasil pengujian pada tabel diatas nilai tolerance masing-masing variabel bebas yaitu $0,759<1,0$ dan nilai Variance Inflation Factor (VIF) sebesar $1,317<10$, dengan demikian model regresi ini tidak terjadi multikolinearitas.

\section{c. Uji Autokorelasi}

Pengujian Autokorelasi digunakan untuk mengetahui ada atau tidaknya penyimpangan korelasi antar anggota sampel. Pengujian dilakukan dengan alat uji Darbin-Watson (DW test). Adapun hasil pengujiannya sebagai berikut:

Tabel 4 Hasil Uji Autokorelasi

\begin{tabular}{|c|c|c|c|c|c|}
\hline \multicolumn{6}{|c|}{ Model Summary $^{\mathbf{b}}$} \\
\hline Iodel & $\mathrm{R}$ & $\begin{array}{c}\mathrm{R} \\
\text { Square }\end{array}$ & $\begin{array}{l}\text { Adjusted } \\
\text { R Square }\end{array}$ & $\begin{array}{l}\text { Std. Error } \\
\text { of the } \\
\text { Estimate }\end{array}$ & $\begin{array}{l}\text { Durbin- } \\
\text { Watson }\end{array}$ \\
\hline & $.748^{\mathrm{a}}$ & .559 & .54 & 2.450 & 1.908 \\
\hline
\end{tabular}

a. Predictors: (Constant), Disiplin Kerja (X2), Motivasi (X1)

b. Dependent Variable: Produktivitas Karyawan (Y)

Hasil pengujian pada tabel diatas diperoleh nilai Durbin-Watson sebesar 1.908 nilai tersebut berada diantara interval $1.550-$ 2.460. Dengan demikian model regresi dinyatakan tidak ada gangguan autokorelasi.

\section{d. Uji Heteroskesdastisitas}

Pengujian heteroskedastisitas dimaksudkan untuk menguji apakah dalam sebuah model regresi terjadi ketidaksamaan varians residual. Hasil pengujiannya sebagai berikut:
Tabel 5. Hasil Uji Heteroskesdastisitas dengan Glejser Test Model

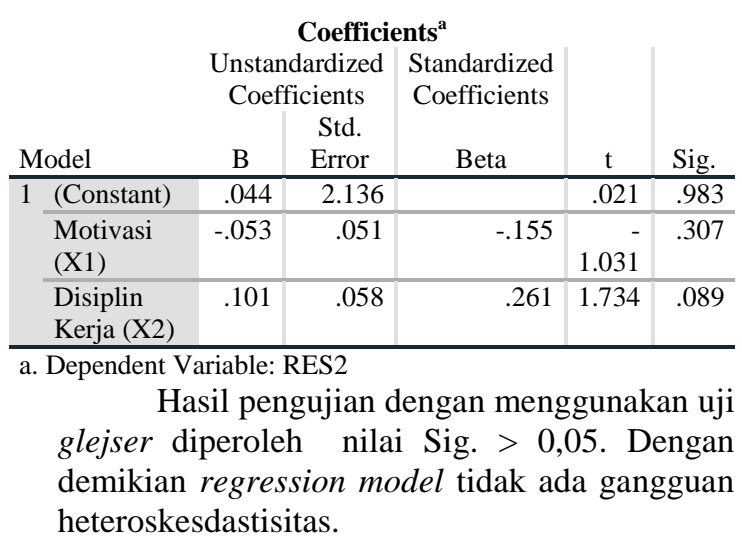

\section{Analisis Deskriptif}

Pada pengujian ini digunakan untuk mengetahui skor minimum dan maksimum, mean score dan standar deviasi dari masing-masing variabel. Adapun hasilnya sebagai berikut:

Tabel 6. Hasil Analisis Descriptive Statistics

\begin{tabular}{|c|c|c|c|c|c|}
\hline \multicolumn{6}{|c|}{ Descriptive Statistics } \\
\hline & $\mathrm{N}$ & Minimum & Maximum & Mean & $\begin{array}{c}\text { Std. } \\
\text { Deviation }\end{array}$ \\
\hline Motivasi (X1) & 58 & 31 & 48 & 38.33 & 4.330 \\
\hline $\begin{array}{l}\text { Disiplin Kerja } \\
\text { (X2) }\end{array}$ & 58 & 31 & 48 & 38.36 & 3.815 \\
\hline $\begin{array}{l}\text { Produktivitas } \\
\text { Karyawan } \\
\text { (Y) }\end{array}$ & 58 & 33 & 46 & 39.31 & 3.624 \\
\hline $\begin{array}{l}\text { Valid N } \\
\text { (listwise) }\end{array}$ & 58 & & & & \\
\hline
\end{tabular}

Motivasi diperoleh varians minimum sebesar 31 dan varians maximum 48 dengan mean score sebesar 3,83 dengan standar deviasi 4,330 .

Disiplin kerja diperoleh varians minimum sebesar 31 dan varians maximum 48 dengan mean score sebesar 3,83 dengan standar deviasi 3,815 .

Produktivitas karyawan diperoleh varians minimum sebesar 33 dan varians maximum 46 dengan mean score sebesar 3,93 dengan standar deviasi 3,624.

4. Analisis Verifikatif.

Pada analisis ini dimaksudkan untuk mengetahui pengaruh variabel independen terhadap variabel dependen. Adapun hasil pengujian sebagai berikut:

\section{a. Analisis Regresi Linier Berganda}

Uji regresi ini dimaksudkan untuk mengetahui perubahan variabel dependen jika variabel independen mengalami perubahan. Adapun hasil pengujiannya 
sebagai berikut:

Tabel 7. Hasil Pengujian Regresi Linier Berganda

\begin{tabular}{|c|c|c|c|c|c|}
\hline & & effi & & & \\
\hline & $\begin{array}{l}\text { Unstan } \\
\text { Coeff }\end{array}$ & $\begin{array}{l}\text { dardized } \\
\text { icients }\end{array}$ & $\begin{array}{l}\text { Standardized } \\
\text { Coefficients }\end{array}$ & & \\
\hline Model & B & $\begin{array}{l}\text { Std. } \\
\text { Error }\end{array}$ & Beta & $\mathrm{t}$ & Sig. \\
\hline 1 (Constant) & 10.188 & 3.589 & & 2.839 & .006 \\
\hline $\begin{array}{l}\text { Motivasi } \\
\text { (X1) }\end{array}$ & .429 & .086 & .512 & 4.985 & .000 \\
\hline $\begin{array}{l}\text { Disiplin } \\
\text { Kerja (X2) }\end{array}$ & .331 & .098 & .348 & 3.388 & .001 \\
\hline $\begin{array}{r}\text { Dependent } \\
\text { Berd } \\
\text { atas, } \\
10,1 \\
\text { pers } \\
\text { berik }\end{array}$ & $\begin{array}{l}\text { Variable: } \mathrm{P} \\
\text { dasarkan } \\
\text { diperol } \\
88+ \\
\text { amaan } \\
\text { kut: }\end{array}$ & $\begin{array}{l}\text { roduktivit } \\
\text { hasil pe } \\
\text { eh pers } \\
0,429 \mathrm{X} 1 \\
\text { tersebut }\end{array}$ & $\begin{array}{l}\text { as Karyawan } \\
\text { engujian pa } \\
\text { samaan reg } \\
+\quad 0,33 \\
\text { dijelaska }\end{array}$ & $\begin{array}{l}\text { Y) } \\
\text { da tab } \\
\text { gresi } \\
1 X 2 . \\
\text { n seb }\end{array}$ & $\begin{array}{l}\text { el di } \\
Y= \\
\text { Dari } \\
\text { bagai }\end{array}$ \\
\hline 1) & $\begin{array}{l}\text { Konstant } \\
\text { motivasi } \\
\text { maka tel } \\
\text { karyawar }\end{array}$ & $\begin{array}{l}\text { a sebesa } \\
\text { dan dis } \\
\text { ah terda } \\
\text { a sebesar }\end{array}$ & $\begin{array}{l}\text { Ir } 10,188 \text { di } \\
\text { siplin kerja } \\
\text { apat nilai p } \\
10,188 \text { poi }\end{array}$ & $\begin{array}{l}\text { artikan } \\
\text { tidak } \\
\text { rodukti } \\
\text { nt. }\end{array}$ & $\begin{array}{l}\text { jika } \\
\text { ada, } \\
\text { ivitas }\end{array}$ \\
\hline 2) & $\begin{array}{l}\text { Koefisier } \\
0,429, \text { ar } \\
\text { ada penir } \\
\text { maka pro } \\
\text { mengalar } \\
\text { point. }\end{array}$ & $\begin{array}{l}\text { regre } \\
\text { igka ini } \\
\text { lgkatan } \\
\text { duktivit } \\
\text { ni penir }\end{array}$ & $\begin{array}{l}\text { esi motiva } \\
\text { motivasi se } \\
\text { as karyawa } \\
\text { ngkatan seb }\end{array}$ & $\begin{array}{l}\text { si sel } \\
\text { inya s } \\
\text { besar } 0 \\
\text { n juga } \\
\text { besar } 0\end{array}$ & $\begin{array}{l}\text { besar } \\
\text { setiap } \\
0,429 \\
\text { akan } \\
0,429\end{array}$ \\
\hline 3) & $\begin{array}{l}\text { Koefisier } \\
0,331 \text {, a } \\
\text { ada peni } \\
0,331 \quad \mathrm{n} \\
\text { juga ak } \\
\text { sebesar }\end{array}$ & \begin{tabular}{l}
\multicolumn{2}{c}{ regresi } \\
gka ini \\
ngkatan \\
laka pr \\
an me \\
,331 poi
\end{tabular} & $\begin{array}{l}\text { disiplin ke } \\
\text { positif art } \\
\text { disiplin ke } \\
\text { roduktivitas } \\
\text { engalami } \\
\text { int. }\end{array}$ & $\begin{array}{l}\text { erja sel } \\
\text { inya s } \\
\text { rja sel } \\
\text { karya } \\
\text { peningk }\end{array}$ & $\begin{array}{l}\text { besar } \\
\text { etiap } \\
\text { besar } \\
\text { awan } \\
\text { katan }\end{array}$ \\
\hline
\end{tabular}

\section{b. Analisis Koefisien Korelasi}

Analisis koefisien korelasi dimaksudkan untuk mengetahui tingkt kekuatan hubungan dari variabel independen terhadap variabel dependen baik secara parsial maupun simultan. Adapun hasil pengujian sebagai berikut:

Tabel 8. Hasil Pengujian Koefisien Korelasi Motivasi Terhadap Produktivitas Karyawan.

\begin{tabular}{|c|c|c|c|}
\hline \multicolumn{4}{|c|}{ Correlations $^{\mathrm{b}}$} \\
\hline & & $\begin{array}{c}\text { Motivasi } \\
\text { (X1) }\end{array}$ & $\begin{array}{c}\text { Produktivitas } \\
\text { Karyawan } \\
\text { (Y) }\end{array}$ \\
\hline \multirow[t]{2}{*}{ Motivasi (X1) } & $\begin{array}{l}\text { Pearson } \\
\text { Correlation }\end{array}$ & 1 & $.683^{* *}$ \\
\hline & $\begin{array}{l}\text { Sig. (2- } \\
\text { tailed) }\end{array}$ & & .000 \\
\hline \multirow[t]{2}{*}{$\begin{array}{l}\text { Produktivitas } \\
\text { Karyawan (Y) }\end{array}$} & $\begin{array}{l}\text { Pearson } \\
\text { Correlation }\end{array}$ & $.683^{* *}$ & 1 \\
\hline & $\begin{array}{l}\text { Sig. (2- } \\
\text { tailed) }\end{array}$ & .000 & \\
\hline
\end{tabular}

Berdasarkan hasil pengujian diperoleh nilai korelasi sebesar 0,683 artinya motivasi memiliki hubungan yang kuat terhadap produktivitas karyawan.

Tabel 9. Hasil Pengujian Koefisien Korelasi Disiplin kerja Terhadap Produktivitas Karyawan.

\begin{tabular}{|c|c|c|c|}
\hline \multicolumn{4}{|c|}{ Correlations $^{b}$} \\
\hline & & $\begin{array}{l}\text { Disiplin } \\
\text { Kerja } \\
(\mathrm{X} 2)\end{array}$ & $\begin{array}{c}\text { Produktivitas } \\
\text { Karyawan } \\
\text { (Y) }\end{array}$ \\
\hline \multirow[t]{2}{*}{$\begin{array}{l}\text { Disiplin Kerja } \\
\text { (X2) }\end{array}$} & $\begin{array}{l}\text { Pearson } \\
\text { Correlation }\end{array}$ & 1 & $.600^{* *}$ \\
\hline & Sig. (2-tailed) & & .000 \\
\hline \multirow[t]{2}{*}{$\begin{array}{l}\text { Produktivitas } \\
\text { Karyawan (Y) }\end{array}$} & $\begin{array}{l}\text { Pearson } \\
\text { Correlation }\end{array}$ & $.600^{* *}$ & 1 \\
\hline & Sig. (2-tailed) & .000 & \\
\hline
\end{tabular}

**. Correlation is significant at the 0.01 level (2-tailed).

b. Listwise $\mathrm{N}=58$

Berdasarkan hasil pengujian diperoleh nilai korelasi sebesar 0,600 artinya disiplin kerja memiliki hubungan yang kuat terhadap produktivitas karyawan.

Tabel 10. Hasil Pengujian Koefisien Korelasi Motivasi dan Disiplin kerja secara simultan Terhadap Produktivitas Karyawan.

\begin{tabular}{|c|c|c|c|c|}
\hline \multicolumn{5}{|c|}{ Model Summary } \\
\hline Io & $\mathrm{R}$ & $\begin{array}{c}\mathrm{R} \\
\text { Square }\end{array}$ & $\begin{array}{c}\text { Adjusted } \\
\text { R } \\
\text { Square }\end{array}$ & $\begin{array}{l}\text { Std. Error of } \\
\text { the Estimate }\end{array}$ \\
\hline 1 & $.748^{\mathrm{a}}$ & .559 & .543 & 2.450 \\
\hline
\end{tabular}

a. Predictors: (Constant), Disiplin Kerja (X2),

Motivasi (X1)

Berdasarkan hasil pengujian diperoleh nilai korelasi sebesar 0,748 artinya motivasi dan disiplin kerja secara simultan memiliki hubungan yang kuat terhadap produktivitas karyawan.

\section{c. Analisis Koefisien Determinasi}

Analisis koefisien determinasi dimaksudkan untuk mengetahui besarnya persentase pengaruh dari variabel independen terhadap variabel dependen baik secara parsial maupun simultan. Adapun hasil pengujian sebagai berikut: 
Tabel 11. Hasil Pengujian Koefisien Determinasi Motivasi Terhadap Produktivitas Karyawan.

\begin{tabular}{|c|c|c|c|c|}
\hline \multicolumn{5}{|c|}{ Model Summary } \\
\hline Model & $\mathrm{R}$ & $\begin{array}{c}\mathrm{R} \\
\text { Square }\end{array}$ & $\begin{array}{c}\text { Adjusted } \\
\text { R } \\
\text { Square }\end{array}$ & $\begin{array}{c}\text { Std. } \\
\text { Error of } \\
\text { the } \\
\text { Estimate }\end{array}$ \\
\hline 1 & $.683^{\mathrm{a}}$ & .467 & .457 & 2.669 \\
\hline
\end{tabular}

a. Predictors: (Constant), Motivasi (X1)

Berdasarkan hasil pengujian diperoleh nilai determinasi sebesar 0,467 artinya motivasi memiliki kontribusi pengaruh sebesar $46,7 \%$ terhadap produktivitas karyawan.

Tabel 13. Hasil Pengujian Koefisien Determinasi Disiplin kerja Terhadap Produktivitas Karyawan.

\begin{tabular}{|c|c|c|c|c|}
\hline \multicolumn{5}{|c|}{ Model Summary } \\
\hline Model & $\mathrm{R}$ & $\begin{array}{c}\mathrm{R} \\
\text { Square }\end{array}$ & $\begin{array}{l}\text { Adjusted } \\
\text { R } \\
\text { Square }\end{array}$ & $\begin{array}{l}\text { Std. Error } \\
\text { of the } \\
\text { Estimate }\end{array}$ \\
\hline 1 & $.600^{\mathrm{a}}$ & .360 & .348 & 2.925 \\
\hline \multicolumn{5}{|c|}{ a. Predictors: (Constant), Disiplin Kerja (X2) } \\
\hline \multirow{2}{*}{\multicolumn{5}{|c|}{$\begin{array}{l}\text { Berdasarkan hasil pengujian diperoleh } \\
\text { i determinasi sebesar } 0,360 \text { artinya }\end{array}$}} \\
\hline & & & & \\
\hline \multirow{3}{*}{\multicolumn{5}{|c|}{$\begin{array}{l}\text { disiplin kerja memiliki kontribusi pengaruh } \\
\text { sebesar } 36,0 \% \text { terhadap produktivitas } \\
\text { karyawan. }\end{array}$}} \\
\hline & & & & \\
\hline & & & & \\
\hline \multicolumn{5}{|c|}{ Tabel 14.} \\
\hline \multicolumn{5}{|c|}{ Determinasi Motivasi dan Disiplin kerja } \\
\hline
\end{tabular}

\begin{tabular}{|c|c|c|c|c|}
\hline \multicolumn{5}{|c|}{ Model Summary } \\
\hline Model & $\mathrm{R}$ & $\begin{array}{c}\mathrm{R} \\
\text { Square }\end{array}$ & $\begin{array}{c}\text { Adjusted } \\
\text { R } \\
\text { Square }\end{array}$ & $\begin{array}{c}\text { Std. } \\
\text { Error of } \\
\text { the } \\
\text { Estimate }\end{array}$ \\
\hline 1 & $.748^{\mathrm{a}}$ & .559 & .543 & 2.450 \\
\hline
\end{tabular}

Berdasarkan hasil pengujian diperoleh nilai determinasi sebesar 0,559 artinya motivasi dan disiplin kerja secara simultan memiliki kontribusi pengaruh sebesar 55,9\% terhadap produktivitas karyawan, sedangkan sisanya sebesar $44,1 \%$ dipengaruhi faktor lain.

\section{d. Uji Hipotesis}

Uji hipotesis Parsial (Uji t)

Pengujian hipotesis dengan uji t digunakan untuk mengetahui hipotesis parsial mana yang diterima.
Hipotesis pertama: Terdapat pengaruh yang signifikan antara motivasi terhadap produktivitas karyawan.

Tabel 15. Hasil Uji Hipotesis Motivasi Terhadap Produktivitas Karyawan.

\section{Coefficients $^{\mathrm{a}}$}

\begin{tabular}{|c|c|c|c|c|c|}
\hline & \multicolumn{2}{|c|}{$\begin{array}{c}\text { Unstandardiz } \\
\text { ed } \\
\text { Coefficients }\end{array}$} & \multirow{2}{*}{$\begin{array}{c}\text { Standardiz } \\
\text { ed } \\
\text { Coefficien } \\
\text { ts } \\
\text { Beta } \\
\end{array}$} & \multirow[b]{2}{*}{$t$} & \multirow[b]{2}{*}{ Sig } \\
\hline Model & B & $\begin{array}{l}\text { Std. } \\
\text { Error }\end{array}$ & & & \\
\hline $\begin{array}{l}1 \text { (Consta } \\
\mathrm{nt})\end{array}$ & $\begin{array}{r}17.39 \\
5 \\
\end{array}$ & 3.149 & & $\begin{array}{r}5.52 \\
4 \\
\end{array}$ & $\begin{array}{r}.00 \\
0 \\
\end{array}$ \\
\hline $\begin{array}{l}\text { Motivasi } \\
\text { (X1) }\end{array}$ & .572 & .082 & .683 & $\begin{array}{r}7.00 \\
3\end{array}$ & $\begin{array}{r}.00 \\
0 \\
\end{array}$ \\
\hline
\end{tabular}

a. Dependent Variable: Produktivitas Karyawan (Y)

\begin{tabular}{|c|c|c|c|c|c|}
\hline \multicolumn{6}{|c|}{ Coefficients $^{a}$} \\
\hline & \multicolumn{2}{|c|}{$\begin{array}{l}\text { Unstandardiz } \\
\text { ed } \\
\text { Coefficients }\end{array}$} & $\begin{array}{l}\text { Standardiz } \\
\text { ed } \\
\text { Coefficien } \\
\text { ts }\end{array}$ & \multirow[b]{2}{*}{$\mathrm{t}$} & \multirow[b]{2}{*}{ Sig } \\
\hline Model & B & $\begin{array}{l}\text { Std. } \\
\text { Error }\end{array}$ & Beta & & \\
\hline $\begin{array}{l}1 \text { (Consta } \\
\text { nt) }\end{array}$ & $\begin{array}{r}17.5 \\
17\end{array}$ & 2.774 & & $\begin{array}{r}6.31 \\
6\end{array}$ & $\begin{array}{r}.00 \\
0\end{array}$ \\
\hline $\begin{array}{l}\text { Motivas } \\
\text { i (X1) }\end{array}$ & .565 & .072 & .649 & $\begin{array}{r}7.80 \\
9\end{array}$ & $\begin{array}{r}.00 \\
0\end{array}$ \\
\hline \multicolumn{6}{|c|}{$\begin{array}{l}\text { a. Dependent Variable: Produktivitas Karyawan } \\
\text { (Y) }\end{array}$} \\
\hline \multirow{2}{*}{\multicolumn{6}{|c|}{$\begin{array}{l}\text { Berdasarkan hasil pengujian pada } \\
\text { tabel di atas, diperoleh nilai t hitung }>\text { t tabel } \\
\text { atau }(7,809>2,003) \text {, dengan demikian } \\
\text { hipotesis pertama yang diajukan bahwa } \\
\text { terdapat pengaruh yang signifikan atara } \\
\text { motivasi terhadap produktivitas karyawan } \\
\text { diterima. }\end{array}$}} \\
\hline & & & & & \\
\hline \multicolumn{6}{|c|}{$\begin{array}{l}\text { Tabel 16. Hasil Uji Hipotesis Disiplin kerja } \\
\text { Terhadap Produktivitas Karyawan. }\end{array}$} \\
\hline \multicolumn{6}{|c|}{ Coefficients $^{\text {a }}$} \\
\hline & $\begin{array}{r}\text { Unstai } \\
\text { Coeff }\end{array}$ & $\begin{array}{l}\text { dardiz } \\
\text { d cients }\end{array}$ & $\begin{array}{l}\text { Standardiz } \\
\text { ed } \\
\text { Coefficien } \\
\text { ts }\end{array}$ & & \\
\hline Model & B & $\begin{array}{l}\text { Std. } \\
\text { Error }\end{array}$ & Beta & $\mathrm{t}$ & Sig \\
\hline $\begin{array}{l}1 \text { (Consta } \\
\text { nt) }\end{array}$ & $\begin{array}{r}17.4 \\
57 \\
\end{array}$ & 3.916 & & $\begin{array}{r}4.45 \\
8\end{array}$ & $\begin{array}{r}.00 \\
0\end{array}$ \\
\hline
\end{tabular}




\begin{tabular}{l|r|r|r|r|r}
\hline $\begin{array}{l}\text { Disiplin } \\
\begin{array}{l}\text { Kerja } \\
\text { X2) }\end{array}\end{array}$ & .570 & .102 & .600 & 5.60 & .00 \\
\hline
\end{tabular}

a. Dependent Variable: Produktivitas Karyawan (Y)

Berdasarkan hasil pengujian pada tabel di atas, diperoleh nilai $\mathrm{t}$ hitung $>\mathrm{t}$ tabel atau $(5,608>2,003)$, dengan demikian hipotesis kedua yang diajukan bahwa terdapat pengaruh yang signifikan atara disiplin kerja terhadap produktivitas karyawan diterima.

\section{Uji Hipotesis Simultan (Uji F)}

Pengujian hipotesis dengan uji $\mathrm{F}$ digunakan untuk mengetahui hipotesis simultan yang mana yang diterima.

Hipotesis ketiga Terdapat pengaruh yang signifikan antara motivasi dan disiplin kerja terhadap produktivitas karyawan.

Tabel 17. Hasil Uji Hipotesis Motivasi dan Disiplin kerja Terhadap Produktivitas Karyawan.

\begin{tabular}{lr|r|r|r|r}
\multicolumn{7}{c}{ ANOVA } & \multicolumn{1}{c}{} \\
\multicolumn{1}{c}{$\begin{array}{c}\text { Sum of } \\
\text { Square }\end{array}$} & & Mean & & \\
Model & \multicolumn{1}{c}{$\mathrm{s}$} & df & Square & F & Sig. \\
\hline 1 Regressio & 418.30 & 2 & 209.15 & 34.84 & .000 \\
$\mathrm{n}$ & 1 & & 1 & 7 & $\mathrm{~b}$ \\
\hline Residual & 330.11 & 5 & 6.002 & & \\
& 3 & 5 & & & \\
\hline Total & 748.41 & 5 & & & \\
& 4 & 7 & & & \\
\hline
\end{tabular}

a. Dependent Variable: Turn Over Intention

Karyawan (Y)

b. Predictors: (Constant), Kepuasan Kerja (X2), Motivasi (X1)

Berdasarkan hasil pengujian pada tabel di atas, diperoleh nilai $\mathrm{F}$ hitung $>\mathrm{F}$ tabel atau (34,847>2,770), dengan demikian hipotesis ketiga yang diajukan bahwa terdapat pengaruh yang signifikan atara motivasi dan disiplin kerja terhadap produktivitas karyawan diterima.

\section{PEMBAHASAN HASIL PENELITIAN}

\section{Pengaruh Motivasi Terhadap Produktivitas} Karyawan

Dari hasil analisis diperoleh variabel motivasi berpengaruh signifikan terhadap produktivitas karyawan dengan nilai korelasi sebesar 0,683 artinya kedua variabel memiliki hubungan yang kuat dengan kontribusi pengaruh sebesar $46,7 \%$. Pengujian hipotesis diperoleh nilai $\mathrm{t}$ hitung $>\mathrm{t}$ tabel atau $(7,809>$ 2,003). Dengan demikian hipotesis pertama yang diajukan bahwa terdapat berpengaruh signifikan antara motivasi terhadap produktivitas karyawan diterima.

\section{Pengaruh Disiplin kerja Terhadap Produktivitas Karyawan}

Dari hasil analisis diperoleh variabel disiplin kerja berpengaruh signifikan terhadap produktivitas karyawan dengan nilai korelasi sebesar 0,600 artinya kedua variabel memiliki hubungan yang kuat dengan kontribusi pengaruh sebesar $36,0 \%$. Pengujian hipotesis diperoleh nilai $\mathrm{t}$ hitung $>\mathrm{t}$ tabel atau $(5,608>$ 2,003). Dengan demikian hipotesis kedua yang diajukan bahwa terdapat berpengaruh signifikan antara disiplin kerja terhadap produktivitas karyawan diterima.

3. Pengaruh Motivasi dan Disiplin kerja Terhadap Produktivitas Karyawan

Dari hasil analisis diperoleh variabel motivasi dan disiplin kerja berpengaruh signifikan terhadap produktivitas karyawan dengan diperoleh persamaan regresi $\mathrm{Y}=10,188$ $+0,429 \mathrm{X} 1+0,331 \mathrm{X} 2$, nilai korelasi sebesar 0,748 artinya kedua variabel memiliki hubungan yang kuat dengan kontribusi pengaruh sebesar $55,9 \%$ sedangkan sisanya sebesar $44,1 \%$ dipengaruhi faktor lain. Pengujian hipotesis diperoleh nilai $\mathrm{F}$ hitung $>\mathrm{F}$ tabel atau $(34,847>$ 2,770 ). Dengan demikian hipotesis ketiga yang diajukan bahwa terdapat berpengaruh signifikan antara motivasi dan disiplin kerja terhadap produktivitas karyawan diterima.

\section{PENUTUP}

\section{Kesimpulan}

a. Motivasi berpengaruh signifikan terhadap produktivitas karyawan nilai korelasi sebesar 0,683 atau kuat dengan kontribusi pengaruh sebesar $46,7 \%$. Uji hipotesis diperoleh nilai $\mathrm{t}$ hitung > $\mathrm{t}$ tabel atau $(7,809>2,003)$. Dengan demikian terdapat pengaruh yang signifikan antara motivasi terhadap produktivitas karyawan pada PT. Mediaindo Sejahtera di Jakarta.

b. Disiplin kerja berpengaruh signifikan terhadap produktivitas karyawan dengan nilai korelasi sebesar 0,600 atau kuat dengan kontribusi pengaruh sebesar $36,0 \%$. Uji hipotesis diperoleh nilai $\mathrm{t}$ hitung $>\mathrm{t}$ tabel atau $(5,608>2,003)$. Dengan demikian terdapat pengaruh yang signifikan antara 
disiplin kerja terhadap produktivitas karyawan pada PT. Mediaindo Sejahtera di Jakarta.

c. Motivasi dan disiplin kerja berpengaruh signifikan terhadap produktivitas karyawan dengan nilai korelasi sebesar 0,748 atau kuat dengan kontribusi pengaruh sebesar $55,9 \%$ sedangkan sisanya sebesar $44,1 \%$ dipengaruhi faktor lain. Uji hipotesis diperoleh nilai $\mathrm{F}$ hitung $>\mathrm{F}$ tabel atau $(34,847>2,770)$. Dengan demikian terdapat pengaruh yang signifikan antara motivasi dan disiplin kerja secara simultan terhadap produktivitas karyawan pada PT. Mediaindo Sejahtera di Jakarta.

2. Saran

a. Perusahaan harus senantiasa mendorong karyawan dalam hal semangat dalam melaksanakan kewajiban dan tugas pekerjaannya

b. Peraturan harus benar-benar diterapkan tanpa memandang posisi jabatan seseorang sehingga karyawan melihat ada keseriusan dalam penegakan disiplin di perusahaan

c. Perusahaan harus mendorong karyawan memiliki perhitungan dalam menyelesaikan pekerjaannya sehingga tepat waktu 


\section{REFERENSI}

A.A Anwar Prabu Mangkunegara, "Evaluasi Produktivitas SDM”. PT Refika Aditama, Bandung, 2017.

A Sobarna, S Hambali, S Sutiswo, D Sunarsi. (2020). The influence learning used ABC run exercise on the sprint capabilities. Jurnal Konseling dan Pendidikan 8 (2), 67-71

Algifari. (2015). “Analisis Regresi untuk Bisnis dan Ekonomi”. Yogyakarta: BPFE.

Amir, Mohammad Faisal, "Manajemen Produktivitas Perguruan Tinggi”, Mitra Wacana Media, Jakarta, 2016.

Andani, M., Sarwani, S., \& Respati, N. W. (2019). Pengaruh Karakteristik Pemerintah Daerah Dan Opini Audit Terhadap Kinerja Pemerintah Provinsi Di Indonesia. Jurnal Akuntansi, 9(2), 111-130.

Andi Supangat, "Statistika dalam Kajian Deskriftif, Inferensi dan Non Parametric", Edisi Pertama, Kencana Prenada Media Group, Jakarta, 2014.

Arikunto, Suharsimi (2014). "Prosedur Penelitian Suatu Pendekatan Praktek". Jakarta: Rineka Cipta.

Bungin, Burhan, “Metodologi Penelitian Sosial dan Ekonomi”, Prenada Media Group, Jakarta, 2013.

Chairina, C., \& Sarwani, S. (2019). Accounting Treatment of Biological Assets in Plantation Industry on Wetlands (Case Study in Plantation Company Entities in South Kalimantan). Journal of Wetlands Environmental Management, 6(2), 110-120.

D Prasada, S Sarwani, M Catio. (2019). Pengaruh Kompensasi Dan Lingkungan Kerja Terhadap Kinerja Karyawan Pada PT. Mitra Adiperkasa, Tbk. Jurnal Manajemen, Bisnis dan Organisasi (JUMBO) 3 (3), 195-207

D Sunarsi. (2014). Pengaruh Gaya Kepemimpinan, Motivasi dan Disiplin Kerja Terhadap Kinerja Pendidik. Universitas Pamulang

D Sunarsi. (2016). Hubungan Pengendalian Diri dengan Prestasi Belajar. Penelitian. Fakultas Ekonomi Universitas Pamulang

D Sunarsi. (2020). Kepemimpinan Bisnis Strategik. Kota Serang: Desanta Muliavisitama

Edi Sutrisno“Sumber Daya Manusia”, PT. Gramedia, Surabaya, 2012.

Gumilar, I., Sunarsi, D. (2020). Comparison of financial performance in banking with high car and low car (Study of banks approved in the kompas 100 index for the period 2013-2017). International Journal of Psychosocial Rehabilitation. Volume 24 - Issue 7

Imam Ghozali (2017). “Aplikasi Analisis Multivariate Dengan Program SPSS”. Edisi Kelima. Semarang: Badan Penerbit Undip.

Istijanto (2014) "Riset Sumber Daya Manusia". Jakarta: PT. Gramedia Pustaka

Maddinsyah, A., Sunarsi, D., Hermawati, R., Pranoto. (2020). Analysis of location selection effect on the user decision that influcence the success of the service business of micro, small and medium enterprise (MSME) in bandung timur region. International Journal of Advanced Science and Technology. Vol. 29 No. 06

Santoso, Singgih (2015). "Menguasai Statistik Multivariat”. Jakarta: PT Elex Media Komputindo.

Sobarna, A. (2016). Model Pembelajaran Atletik Ditinjau Dari Perspektif Pedagogik Penjas (Athletic Learning Model See From Pedagogi Perspektive). Motion: Jurnal Riset Physical Education, 7(1), $15-23$.

Sudjana (2014) "Metode Statistika”, Bandung: Tarsido.

Sugiyono (2017), "Metode Penelitian Administrasi : dilengkapi dengan Metode R \& D". Bandung: Alfabeta.

Sunarsi, D. (2020). The Analysis of The Work Environmental and Organizational Cultural Impact on The Performance and Implication of The Work Satisfaction. Jurnal Ilmiah Ilmu Administrasi Publik, 9(2), 237-246.

Sunarsi, D., \& Erlangga, A. (2020). The Effect of Leadership Style and Work Environment on the Performance of Stationary Pump Operators in the Water Resources Office of West Jakarta City Administration. International Journal of Advances in Social and Economics, 2(3).

Suntoyo, Danang, "Penelitian Sumber Daya Manusia". PT Buku Seru, Jagakarsa, 2015.

Supriadi, D., \& Sobarna, A. (2008). Atletik (Didaktik\&Metodik).

Sutrisno, S., \& Sunarsi, D. (2019). The Effect of Work Motivation and Discipline on Employee Productivity at PT. Anugerah Agung in Jakarta. Jurnal Ad'ministrare, 6(2), 187-196.

Wibowo, "Manajemen Produktivitas-Edisi Ketiga", Rajawali Pers, Jakarta, 2013. 